\title{
A JUDICIALIZAÇÃO DAS REFORMAS PREVIDENCIÁRIAS NA JURISPRUDÊNCIA DO STF: um Tribunal amigo do equilíbrio
}

financeiro e atuarial // Flávia Danielle Santiago Lima ${ }^{1}$ Tassiana Moura de Oliveira²

\author{
Palavras-chave \\ revisão judicial / controle abstrato / previdência social
}

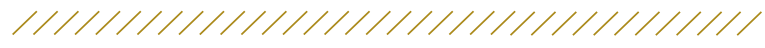

\section{Sumário}

1 Introdução

2 Agenda do Poder Executivo e as decisões do STF em controle de constitucionalidade concentrado: estudos gerais e suas conclusões

3 O histórico de reformas: produto da crise

3.1 A crise da segunda metade da década de 1990 e a EC nº 20 de 1998

3.2 A segunda reforma na previdência: um cenário institucional favorável à EC 41/2003

$4 \quad$ A judicialização do conflito: "equilíbrio atuarial" $\mathrm{x}$ direitos adquiridos, o STF como garantidor da "governabilidade"?

4.1 Analisando as decisões judiciais: o conflito entre o equilíbrio atuarial e direitos adquiridos dos segurados

4.1.1 ADI 1946: teto para a licença maternidade

4.1.2 ADI 2024: cargos em comissão, temporários e empregos públicos como de contribuição obrigatória ao RGPS

ADI 2242: aposentadoria de Magistrados

ADI 2760: aposentadoria compulsória dos Magistrados e Ministros do TCU

4.1.5 ADI 2883: aposentadoria compulsória dos Magistrados e Ministros do TCU

4.1.6 ADI 3104 e 3291: alterações nos critérios de idade e tempo para aposentação

4.1.7 ADI 3105, ADI 3099 e ADI 3128: contribuição de inativos 4.1.8 ADI 3138: limites para alíquotas de contribuição social

4.1.9 ADI 3172: contribuição de inativos

4.1.10 ADI 3867: inaplicabilidade dos novos paradigmas constitucionais à categoria de Fiscal de Rendas do Estado do Rio de Janeiro
Judicial Politics e o ativismo judicial no Brasil

6 Referências

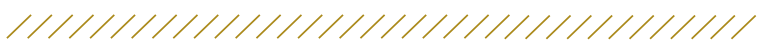

\section{Resumo}

0 presente trabalho procura responder a seguinte questão de pesquisa: qual o princípio constitucional defendido pelo STF nas decisões em matéria previdenciária no controle abstrato de constitucionalidade? $O$ direito social à previdência social tem status de direito fundamental na constituição, contudo é uma prestação onerosa ao Estado. Os Poderes Legislativo e Executivo periodicamente modificam as regras de previdência com o objetivo de conter os gastos. Como Poder contramajoritário, o Poder Judiciário tem o dever de proteger os direitos sociais dos cidadãos impedindo que as decisões tomadas pelos outros poderes retrocedam (ou extingam) direitos conquistados na Carta de 1988. O objetivo do trabalho é saber se o STF (como órgão de cúpula do Judiciário) cumpre esse papel com o direito à Previdência Social. Para tanto, foi realizada uma análise exploratório-descritiva de "n" pequeno sobre as decisões de mérito das Ações Diretas de Inconstitucionalidade propostas contra as Emendas Constitucionais de números 20 de 1998 e 41 de 2003. 0 resultado encontrado foi que o STF, nas decisões analisadas, se preocupou mais em garantir o equilíbrio financeiro e atuarial do sistema do que resguardar os direitos previstos originariamente na constituição de 1988.

1 Doutora em Direito Público (Faculdade de Direito do Recife/ UFPE). Mestrado em Direito (Faculdade de Direito do Recife/UFPE). Professora da Universidade Católica de Pernambuco (UNICAP). Advogada da União, com exercício da Procuradoria Regional da União da 5a Região. E-mail: flavia-santiago@uol.com.br

2 Doutoranda em Ciência Política (Universidade Federal de Pernambuco). Mestrado em Direito (Universidade Católica de Pernambuco). Pesquisadora Bolsista Capes/CNPQ. E-mail: tassioliveira@gmail.com 


\section{THE SOCIAL SECURITY REFORMS JUDICIALIZATION IN THE STF'S DECISIONS: a friendly court for financial and actuarial balance //}

\section{Flávia Danielle Santiago Lima e Tassiana Moura de Oliveira}

\section{Keywords}

judicial review / abstract control / social security

\begin{abstract}
This paper intend to answer the following research question: what is the constitutional principle upheld by the Supreme Court in decisions on social security matters inside Brazilian abstract constitutionality control? The right to social security is has a status of fundamental right in the Brazilian Constitution, but it also is a costly provision for the State. The Legislative and Executive branches periodically change the pension rules in order to contain costs. As a contramajoritarian power, the Judiciary has a duty to protect the citizens' social rights by preventing that decisions taken by the other branches fall back (or terminate) rights guaranteed by the 1988's constitution. The objective of this study is to understand whether the Supreme Court fulfills that role in social security matters. Therefore, we carried out a descriptive exploratory analysis with small " $n$ " on the Unconstitutionality Direct Actions' decisions filed against the Constitutional Amendment numbers 20/1998 and $41 / 2003$. The result we found was that the Supreme Court, in the analysed decisions, was more concerned to ensure financial and actuarial balance of the system than protect the rights envisaged originally in the 1988's constitution.
\end{abstract}




\section{Introdução}

A consolidação da judicialização das relações políticas e sociais no Brasil é verificável pelo fortalecimento e relevância das instituições judiciais e incorporação do discurso jurídico nas interações entre os diversos grupos políticos e sociais. Ao lado dos requisitos normativos, a expectativa quanto às decisões dos tribunais - sobretudo do Supremo Tribunal Federal (STF), no exercício da jurisdição constitucional - foi integrada à prática dos diversos setores, como grupos de interesse e partidos minoritários.

No Brasil, desde 1988, o STF tem sido provocado para analisar a constitucionalidade de normas e opinar sobre políticas públicas das mais diversas naturezas. Segundo Taylor (2007), nos 15 anos entre 1988 e 2002, o Supremo - somente através do instrumento da Ação Direta de Inconstitucionalidade - ADI - concedeu decisões liminares ou de mérito invalidando parcialmente mais de 200 leis federais. Em comparação, entre 1994 e 2002, a Suprema Corte mexicana julgou a constitucionalidade de um pouco mais de 600 leis naquele país usando dois instrumentos parecidos com a ADI, mas invalidou somente 21 leis federais; em toda sua história, a Suprema Corte americana invalidou em torno de 135 leis federais, apenas.

Neste contexto, as respostas do STF viraram tópico especial de discussão, usualmente identificadas como representação da sua tendência ao ativismo ou autocontenção, em suas repercussões para as dinâmicas entre os titulares de poder. A literatura constitucionalista debruça-se, especialmente, sobre as relações entre Judiciário e Legislativo - eixo que concentraria a discussão em torno do caráter contramajoritário da revisão judicial. Aponta-se, assim, para eventual superposição e até invasão das atribuições do Parlamento pelo Tribunal, em prejuízo do sistema democrático, creditado - entre outros fatores - à erosão de sua legitimidade representativa e suas omissões.

Já estudos empíricos (Vianna, 1999; Carvalho Neto, 2005; Costa \& Benvindo, 2014) apontam para uma relevante questão - a intensa judicialização das questões atinentes à Administração Pública - de particular relevância para os Executivos Federal e Estaduais. Diante desta prevalência dos temas de Direito Admi- nistrativo, o STF, no que diz respeito às ADIs, atuaria como um "conselho de Estado do tipo prevalecente em países de configuração unitária", ao estabelecer "padrões de racionalização na administração pública (Vianna et al., 2007, p. 44)”."3

Espelha-se, na via judicial, uma das peculiaridades da CF-88, que consiste na intensa previsão sobre a Administração Pública, por princípios e regras regedores da atividade dos seus agentes e o(s) correspondente(s) estatuto(s) jurídico(s) de sua função (além das regras para sua aposentadoria), dos seus institutos (licitações e contratos, improbidade, concurso público, responsabilidade estatal) e estrutura.

Neste quadro, um grupo de interesse específico se destaca na agenda do STF: os servidores públicos. A normatização de seu regime jurídico na CF-88 permite que estes agentes públicos questionem eventuais tentativas de alteração pela via das emendas constitucionais (EC's) ou a limitação de direitos através da legislação ordinária. No primeiro caso, sob o argumento preferencial da proteção ao direito adquirido (art. $5^{\circ}$, inciso XXXVI), direito fundamental protegido como cláusula pétrea (art. 60, § 4, IV) e oponível ao poder de reforma. Já no segundo caso, estes grupos amparam-se na supremacia constitucional.

A questão ganhou particular impacto na judicialização das reformas levadas a cabo pelo Poder Executivo no sistema de previdência dos servidores públicos, através das Emendas ns 20 e 41 . Na esteira da imensa polêmica e insatisfação que estas provocaram nestes setores, a disputa entre Administração Pública e servidores, pensionistas e aposentados en-

\footnotetext{
3 "A Adin também é recurso institucional estratégico de governo, instituindo, na prática, o Supremo Tribunal Federal como um conselho de Estado do tipo prevalecente em países de configuração unitária". (...) "Embora essa intervenção judicial na legislação dos estados se revista, em geral, de um inequívoco caráter racionalizador - já presente no governo FHC e notavelmente ampliada no governo Lula -, nota-se, pela envergadura com que é praticada, que ela pode ser mais um sinal da emergência de uma tendência, que toma fôlego em várias dimensões da vida social recente, no sentido de 'corrigir' as relações entre a federação e a União em favor desta última". (...) "Na experiência institucional brasileira, o primado da União sobre a federação tem resultado de motivações modernizantes associadas a momentos de autoritarismo político, como nos anos de 1930 e, mais tarde, sob o regime militar no período 1964-1985" (Vianna et al., 2007, p. 44).
} 
controu no STF um terceiro turno (e uma nova arena) de embates.

Com efeito, as duas mencionadas reformas levaram ao STF, no total, vinte e oito ações diretas de inconstitucionalidade, conforme dados coletados da base de dados da pesquisa de Costa \& Benvindo (2014), produzida pela UNB. De acordo com o levantamento, destas ADI's apresentadas, treze tiveram seu mérito julgado; quatro foram julgadas improcedentes; uma não foi conhecida pelo relator; três não foram conhecidas pelo plenário; uma teve seu seguimento negado pelo relator; uma a questão foi considerada prejudicada pelo relator; e, por fim, três foram consideradas procedentes em parte pelo plenário.

Esse trabalho se propõe, portanto, a analisar as decisões das ADI's referentes às ECs 20 e 41 . O objetivo é observar o posicionamento do STF em matéria previdenciária: estaria o Supremo exercendo sua função de protetor dos direitos fundamentais ou o tribunal tende a respeitar as decisões majoritárias, cooperando com as preferências do Poder Executivo?

Para tal fim, são analisadas as treze decisões de mérito em ADI's, tomando-se como variáveis: os (a) autores das ações (legitimados); os (b) princípios defendidos pelas partes; e o (c) princípio vencedor na soma dos votos dos Ministros. O objetivo é analisar o papel do STF na conformação das reformas previdenciárias implementadas pelo Poder Executivo em 1998 e $2003 .{ }^{4}$

Parte-se da hipótese de que, neste caso, o STF enquadra-se no argumento comum na literatura mundial sobre os tribunais: mais que oposição, sua atuação é marcada pela anuência às escolhas dos legisladores e administradores (Friedman, 2005). No caso brasileiro, pesquisas como a de Taylor (2007) mostram que o STF, em particular, tem agido de forma muito cautelosa e até conservadora para evitar alargar potenciais conflitos com o Executivo. Esse argumento é possível, já que eles não podem atuar sem correr o risco de perder seu poder para um Executivo cioso das próprias prerrogativas.

4 As ADI's analisadas são as de seguintes números: 1946; 2024 2242; 2760; 2883; 3099; 3105; 3128; 3104; 3291; 3172; 3138 e 3867.
A análise destas decisões permite avaliar um dos pontos mais relevantes e controvertidos trazidos pelos estudos acumulados ao longo das últimas décadas: o privilégio das questões de direito administrativo, especialmente do tema servidor público, no controle concentrado de constitucionalidade. E, como consequência, a exploração deste viés específico das relações entre os poderes do Brasil.

Ao longo dos anos 90, o histórico papel protagonista do Executivo na condução do debate político brasileiro ganhou maior repercussão com a adesão ao projeto neoliberal, que implicava na redução das expectativas em torno do caráter redistributivo da Constituição. E a atuação do Judiciário passou a receber ainda mais atenção por parte dos dois grupos.

\section{$2 \quad$ Agenda do Poder Executivo e as decisões do STF em controle de constitucionalidade concentrado: estudos gerais e suas conclusões}

No jogo da separação de poderes, reconhece-se que todas as instituições têm preferências, mas também levam em conta, ao agir, as preferências dos outros ramos. Tem-se, assim, uma reação antecipada (Friedman, 2005 p. 311). Há uma antecipação das instituições sobre qual poderia ser a resposta às suas ações por parte de outros poderes. Assim, é possível que a ação seja mais contida do que seria, para que não haja um impacto negativo nos demais poderes.

O Poder Judiciário não está imune às possíveis reações dos demais poderes decorrentes de suas decisões. É sabido que existe uma "relação assimétrica entre o Parlamento e a corte" (Carvalho Neto, 2005, p. 318), que pode com uma decisão revogar uma lei, mas para que o parlamento derrube sua decisão, tem que passar pelos procedimentos de emenda constitucional ou de alteração legal. Contudo, a vantagem do judiciário não o impede de se preocupar com constrangimentos aos quais ele pode passar, interna ou externamente. "Juízes podem ser impedidos, jurisdições podem ser retiradas, cortes podem ser 'embaladas', e o orçamento do judiciário pode ser cortado" (Friedman, 2005, p. 314).

Uma resposta menos gravosa pode ser também a 
criação de uma norma que vá de encontro àquela decisão criadora de políticas públicas, por exemplo. Por não existir norma que previsse a possibilidade ou impossibilidade de determinado direito, o judiciário a cria e, em resposta, o legislativo, posteriormente, a proíbe. É uma clara reação negativa à decisão do poder judiciário.

Mais do que se preservar dos ataques, as cortes precisam se assegurar de que suas decisões serão cumpridas (Friedman, 2005, p. 315); esse jogo é mais comum quanto ao direito constitucional do que em relação à legislação ordinária. Neste sentido, a corte dispõe de mais informações sobre o que pode ocorrer, especialmente pela antecipação do Poder Executivo. A decisão da corte pode (e geralmente o faz) demandar imediata atitude dos governos com consequências, não apenas políticas, como também financeiras. Caso não haja possibilidade financeira de cumprimento ou não houver vontade política, a decisão pode vir a ser ignorada.

Na prática do controle de constitucionalidade brasileiro, temas de interesse do Poder Executivo são recorrentes nas mesas dos Ministros do STF - em sede de controle concentrado e também difuso. Como demonstra o trabalho de Costa \& Benvindo (2014), a judicialização da política no Brasil envolve sobremaneira temas de interesses institucionais dos litigantes legitimados e da administração pública, estando à frente de tópicos relativos a direitos fundamentais.

No controle concreto, recente pesquisa de Louise Dantas de Andrade (2015, p. 91) concluiu que, comparando a quantidade de processos que interferem no orçamento público com a amostra geral de recursos extraordinários com repercussão geral reconhecida, tem-se que $47,59 \%$ do total de recursos trazem temáticas que influenciam diretamente no orçamento dos entes federados.

O STF, na escolha dos temas de repercussão geral, não apenas deixa de incluir em sua agenda de julgamento os casos que discutem a aplicação e a efetivação de direitos fundamentais, como funciona praticamente como um órgão regulador da inclusão de despesas nas contas governamentais, sejam federais, estaduais ou municipais (Andrade, 2015, p. 91).
No caso dos recursos extraordinários, a preocupação com a agenda do executivo pode ser notada desde a quantidade de processos que têm sua repercussão geral reconhecida. Boa parte deles são recursos interpostos pela Fazenda Pública. Consequentemente, a quantidade de recursos com mérito julgado também é maior quando o autor é o Poder Executivo.

Enquanto apenas 85 (oitenta e cinco) recursos interpostos por entes privados foram julgados desde a criação do instituto da repercussão geral, 140 (cento e quarenta) dos recursos interpostos pela fazenda pública foram julgados, ficando claro que a prioridade para o tribunal é solucionar as lides que representam algum tipo de interesse do governo instituído em detrimento dos interesses da sociedade civil como um todo (Andrade, 2015, p. 85).

A importância do Poder Judiciário no ambiente político já não é tão contestada. Taylor (2008, p. 01) afirmou que, "no Brasil, o Judiciário tem moldado iniciativas políticas que regulam tudo, desde a representação política do partido à privatização". ${ }^{5}$ Ministros do STF já afirmaram, em entrevistas ou eventos, que o judiciário tem esse papel de, através da jurisdição, resolver problemas da sociedade. ${ }^{6}$

Não por acaso, Matthew Taylor \& Luciano Da Ros (2008), assentados na observação de ações diretas de inconstitucionalidade (ADIs) ajuizadas, identificam, ao lado das ações propostas por partidos políticos opositores - independentemente de sua posição no espectro ideológico, as situações em que a judicialização se presta à "arbitragem de interesses em conflito". A segunda hipótese corresponderia ao "caso da contestação judicial de regras que redistribuam poderes e atribuições entre diferentes entidades e instituições, como partidos políticos, entes federativos e diferentes instâncias do Poder Judiciário".

5 Tradução livre das autoras. Original: "In Brazil, the judiciary has molded policy iniciatives governing everything from political party representation to privatization".

6 "O Judiciário tem a obrigação constitucional de prestar a jurisdição e resolver os problemas que afligem a sociedade", afirmou o Ministro Lewandowski, ao comentar as críticas de gestores da saúde ao crescente volume de decisões judiciais com ordens para o fornecimento de medicamentos, consultas, leitos e outros serviços em evento realizado pelo CNJ na sede do Tribunal de Justiça de São Paulo em 18.05.2015. 
[...] Nesse caso, não se trata tanto de fazer uso dos tribunais como instrumentos de oposição ao governo, mas sim de propor ações nos casos em que determinados estatutos legais modifiquem procedimentos e atinjam diretamente interesses de grupos e setores específicos, prejudicando alguns e beneficiando outros. Busca-se o STF como propósito, ainda que não necessariamente declarado e imediato, de definir ou aperfeiçoar determinadas "regras do jogo". A judicialização, nesse caso, não pretende desmerecer a política pública adotada, mas sim alcançar regras procedimentais que beneficiem um determinado ator ou um conjunto deles (Taylor \& Da Ros, 2008, pp. 840-842).

Contudo, a forma de participação é que tem sido, segundo pesquisas quantitativas, apontada como protetora de interesses da administração pública e econômicos, em grande parte, em detrimento de interesses sociais. Aponta-se, por exemplo, o trabalho de Vianna et al. (2007, p. 44) quando diz que "as decisões do STF operam no sentido de garantir a homogeneidade na produção normativa estadual, garantindo-se a prevalência dos princípios e das regras contidos na ampla recepção do direito administrativo operada pela nossa Constituição".

Ricardo Ribeiro (2012) se preocupou em testar o papel conjunto de variáveis de ordem econômica, jurídica e política no processo decisório do órgão de cúpula judicial brasileiro. ${ }^{7}$ Seu trabalho também procurou demonstrar que o STF, ao declarar a constitucionalidade ou inconstitucionalidade de normas, é movido por essas múltiplas variáveis de forma relativamente racionalizada. Na discussão dos resultados do seu estudo, o autor chegou a notar, através de regressão logística, que a única área que significativamente possuiu uma judicialização maior que as outras foi a pertinente ao controle de constitucionalidade das normas sobre o regime jurídico e a disciplina remuneratória dos servidores. No entanto, ele não teve condições metodo- lógicas de chegar à conclusão de que o STF escolhe áreas temáticas para a judicialização.

As conclusões do autor são no sentido de que o Tribunal, a partir de "cânones jurídicos" - especialmente a "jurisprudência pacificada" - atua como um "policy maker, tomando decisões como órgão de governo e não como instituição jurídica neutra ao ambiente econômico e político". Por isso, sua atividade se aproxima ao Chefe do Executivo, uma vez que "declara a inconstitucionalidade de normas que causam impacto orçamentário negativo nas contas estatais, mas evita declarar a inconstitucionalidade de normas que estejam na agenda do Presidente da República" (Ribeiro, 2012, pp. 97-100). ${ }^{8}$

Quanto aos demandantes, a relevância dos partidos políticos, sindicatos e entidades de classe (e estes representam grupos de interesse razoavelmente homogêneos, com predominância dos interesses de carreiras públicas e do setor terciário da economia) é clara, pois correspondem, respectivamente, a $71 \%$ e $80 \%$ das ações de controle concentrado nos casos do Executivo e Legislativo (Sundfeld et al., 2010).

No controle concentrado, de fato, o STF não tem um poder de decidir o que irá receber ou não como tema para judicializar. Depende da atuação dos legitimados constitucionais, consoante previsão do art. 102 da Carta, e também da caracterização da pertinência temática - exigida para alguns destes.

A pesquisa de Costa \& Benvindo (2014) trouxe dados mais recentes sobre o controle concentrado. Segundo o mencionado trabalho, o Presidente da Repúbli$\mathrm{ca}$, como litigante, não tem atuação significativa no STF. O Chefe do Executivo Federal, as Mesas da Câmara e do Senado e as Assembleias Legislativas dos Estados, juntos, respondem por menos de $2 \%$ das ADIs ajuizadas no universo total dos processos.

80 autor agrupou temas como: regime jurídico tributário, das finanças públicas, sistema bancário, planos de estabilização monetária e moeda; benefícios previdenciários do regime geral de previdência social; organização e gerência das administrações direta e indireta; carreira, direitos, deveres e disciplina remuneratória dos servidores públicos e agentes políticos; benefícios previdenciários dos servidores estatutários; disciplina jurídica das privatizações. 
Dentre os demais legitimados, grandes litigantes são o Ministério Público, os partidos políticos e entidades de classe. Muitas das normas impugnadas tiveram como argumento para procedência a competência e respeito ao desenho institucional.

Eles concluíram, analisando as ADIs apresentadas ao STF entre 1988 e 2012, que "quando as decisões ligadas especificamente à garantia dos direitos individuais, coletivos e difusos são isoladas, o resultado é que fica evidente o caráter praticamente residual desses provimentos, tendo em vista que, para a maioria dos Ministros, esses julgamentos representam menos de $5 \%$ das decisões relatadas de procedência".

A conclusão da pesquisa é no sentido de que "o sistema de controle concentrado de constitucionalidade vigente no Brasil possui uma predominância jurisprudencial de argumentos formais ou de organização do Estado, cumulada com uma atuação ligada a direitos fundamentais cuja maior parte é ligada à garantia de interesses corporativos" (Costa \& Benvindo, 2014, p. 78).

Quanto ao interesse do Poder Executivo, o controle de constitucionalidade pode ser utilizado como protetor dos planos do Governo ou como veto player. De acordo com Taylor (2008, p. 75), “veto players são atores políticos (individual ou coletivo) cuja concordância é requerida para promover mudanças políticas". ${ }^{9}$ Assim, o STF tem agido tanto como protetor da política pública, quando, por exemplo, ele se diz incompetente para adentrar na discussão política (como veremos mais à frente na análise das decisões) ou como veto player quando ele se posiciona, seja positiva ou negativamente.

A EC n॰ 20/98 e a EC n 41/2003, ao promoverem substanciais alterações no regime previdenciário dos servidores públicos, inserem-se no contexto das reformas estruturais iniciadas na década de 90, que implicaram em privatização, abertura comercial e desregulamentação, ao transferir "a responsabilidade pelo investimento e pela produção em setores extremamente dependentes de contratação (...), torna-

9 Tradução livre do original: "Veto Players are political actors - an individual ou collective - whose agreement is required to enact policy change". -os mais dependentes do apoio do Poder Judiciário. ${ }^{10}$ Resta saber, no caso específico das políticas públicas previdenciárias, qual o cenário político das reformas promovidas pelas mencionadas emendas, com o resgate de seu histórico, a fim de delimitar os interesses posteriormente levados ao STF em sede de controle de constitucionalidade.

\section{O histórico de reformas: produto da crise}

3.1 A crise da segunda metade da década de 1990 e a EC nº 20 de 1998

A Constituição de 1988 inaugurou um novo cenário para a previdência brasileira, seja no regime geral ou nos regimes próprios. Até então, a aposentadoria era um direito garantido para os trabalhadores e servidores públicos por seus "bons serviços prestados”. Existia a noção de necessidade de comprovação de tempo de serviço; no entanto, a contribuição não era exigida. Por muito tempo na história da previdência dos funcionários públicos, a União concedeu aposentadoria sem fonte de custeio específica. Na verdade, os benefícios previdenciários dos servidores públicos eram tratados como uma compensação pela ausência de políticas remuneratórias e de carreira (Campos, 2011).

A Carta de 1967 trouxe, em seu art. 158, inciso XVI, a previsão da previdência social como um dos direitos dos trabalhadores "mediante contribuição da União, do empregador e do empregado, para seguro-desemprego, proteção da maternidade e, nos casos de doença, velhice, invalidez e morte" e, no inciso $X X$, a possibilidade de aposentadoria para mulher após trinta anos de contribuição. A expressão "previdência" é mencionada outras quatro vezes - na disposição sobre competências legislativas, regras

10 "A extensa presença estatal na economia tornava os contratos menos importantes, pois permitia decidir conflitos e impor regras pela via administrativa, sem a necessidade de se recorrer à Justiça. (...) Nossa pesquisa mostrou que a maioria dos juízes tem consciência de que essas reformas tornaram o seu trabalho mais importante, do ponto de vista econômico, com quase a metade dos magistrados concordando inteiramente com essa tese e um terço tendendo a concordar com ela. (Tabela 7.1)". É importante ressalvar, nas observações de Pinheiro, que o objetivo do trabalho aqui citado é "ajudar a compor um diagnóstico sobre os problemas do Judiciário que mais afetam a economia e a avaliar as iniciativas que podem tornar o Judiciário uma instituição mais eficaz e eficiente do ponto de vista econômico" (Pinheiro, 2005, p. 20). 
de custeio e nas especificidades dos ex-combatentes. Por sua vez, as regras para a aposentadoria dos funcionários públicos estavam descritas no art. 100 e seguintes.

A Constituição de 1988 manteve o termo "tempo de serviço" em seu texto original, mas aumentou consideravelmente o tratamento dado à Previdência Social. Na redação original, havia vinte e quatro citações da expressão "previdência", e dois artigos inteiramente dedicados ao tema: o art. 40, que versa sobre a previdência dos servidores públicos efetivos e o art. 201, que traz as regras constitucionais sobre o regime geral de previdência social.

Mesmo assim, foi apenas em 1998, com a primeira grande reforma previdenciária, que a preocupação com o equilíbrio financeiro e atuarial de fato surgiu no texto constitucional. $\mathrm{O}$ art. 40 , em seu caput, passou a trazer a expressão: "observados critérios que preservem o equilíbrio financeiro e atuarial" para os regimes de previdência próprios com caráter, agora, contributivo. A construção do problema de financiamento dos benefícios foi longa, mas diversas razões concorreram para que, em 1998, fosse concretizada a decisão de mudança no sistema previdenciário brasileiro.

A "bola de neve" já vinha crescendo desde muito tempo. A recessão da década de 1980 e a ampliação da cobertura previdenciária aumentaram o déficit da previdência social (Rocha, 2004). Contudo, os anos de 1997 a 1999 foram mais complexos. O cenário de crise atingia diversas economias emergentes, como a brasileira. Averbug \& Giambiagi (2000, p. 8) expõem os fatores desencadeadores da explosão da crise nestes países, inclusive no Brasil, tais como:

a. um boom de investimento alimentado pelo endividamento crescente das famílias, das empresas e do país;

b. elevada alavancagem dos bancos;

c. ausência de uma supervisão bancária apropriada;

d. taxas de câmbio fixas ou relativamente fixas, em um contexto de déficits crescentes da conta corrente. apaziguar os efeitos da crise e evitar efeitos mais profundos; a primeira destas, privatização das estatais, não se mostrou suficiente para a contenção do excesso de gastos públicos. Aliado à crise financeira internacional, à estagnação do crescimento da economia brasileira que acarretou em um processo de desemprego e informalidade no mercado de trabalho, além do envelhecimento da população, "o sistema previdenciário passou a apresentar déficits significativos" (Rocha, 2004, p. 75). Assim, a reforma da previdência sem contribuição, especialmente por parte dos servidores, já era vislumbrada há muito tempo.

A Emenda Constitucional n 20/98 foi desenhada em um cenário desfavorável e teve um caráter eminentemente restritivo (Rocha, 2004). O primeiro projeto foi enviado ao Congresso em 1995 e era muito mais abrangente. Almejava equilibrar os benefícios previdenciários dos setores público e privado, reduzir privilégios, acirrar critérios de elegibilidade e atacar outros focos que contribuíssem para agravar o déficit fiscal (Nakahodo \& Savoia, 2008). As principais mudanças trazidas pela emenda foram: (a) desconstitucionalização da regra de cálculo do valor dos benefícios; (b) fim das aposentadorias especiais para professores universitários, jornalistas, aeronautas; (c) restrição do salário-família e auxílio reclusão às famílias de comprovada baixa renda; (d) fixação de limite máximo aos benefícios do regime geral (teto da previdência); (e) tentativa de ampliação da previdência complementar; (f) previsão da possibilidade de estabelecimento de um teto, também, para os regimes próprios de previdência; (g) instituição de vedações para a cumulação de proventos de aposentadoria com remuneração; (h) extensão das regras aplicáveis aos servidores públicos para magistrados, promotores e membros do Tribunal de Contas.

Os pontos cruciais, no entanto, referem-se à exigência do tempo mínimo de contribuição (e não de serviço, apenas) e à idade mínima para aposentadoria voluntária (Rocha, 2004).

Os relatos destacam o interesse específico do governo na aplicação da exigência concomitante dos requisitos de tempo de contribuição e idade mínima 
para todos os regimes; contudo, este regime foi aprovado apenas para os servidores públicos. Destarte, a partir de 1998, os servidores, para aposentarem-se voluntariamente, deveriam comprovar o tempo de contribuição e a idade mínimos para homens e mulheres - 35 e 30 anos, 60 e 55 anos, respectivamente.

A alternativa, no Regime Geral de Previdência Social, foi a criação do temido fator previdenciário, através de alteração promovida em 1999 na Lei de Custeio da Previdência Social - Lei n. 8.212/1990. Entre outras novidades, foi estabelecido novo cálculo para os benefícios voluntários, consistente numa média aritmética simples dos maiores salários-de-contribuição correspondentes a $80 \%$ de todo o período contributivo, multiplicada pelo fator previdenciário. Segundo o Ministério da Previdência (Brasil, 2014), o cálculo do fator é baseado em quatro elementos: alíquota de contribuição, idade do trabalhador, tempo de contribuição à Previdência Social e expectativa de sobrevida do segurado (conforme tabela do IBGE).

\subsection{A segunda reforma na previdência: um cenário institucional favorável à EC $41 / 2003$}

A segunda reforma, realizada pelo Presidente Luís Inácio Lula da Silva, deu-se pela aprovação da EC 41 de dezembro de 2003, aprovada em menos de um ano após o início do seu mandato, numa marcada diferença com as dificuldades enfrentadas por Fernando Henrique Cardoso, que enfrentou três anos de oposição no Congresso Nacional e nos setores da sociedade civil organizada. ${ }^{11}$

Nesta segunda reforma, o Poder Judiciário constituiu-se num dos principais obstáculos à aprovação do texto proposto pelo Chefe do Executivo:

No início de seu governo, Lula confrontou o Judiciário numa série de questões, fazendo com que juízes e outros profissionais da Justiça se sentissem particularmente ameaçados com a possibilidade de mudanças em suas aposentadorias. Após assegurar que tais benefícios seriam mantidos, o

11 "Enquanto que Fernando Henrique teve que digladiar por mais de três anos no Congresso até que a reforma fosse promulgada em dezembro de 1998" (Nakahodo \& Savoia, 2008, p. 51). ambiente acalmou-se e o presidente pôde incluir a taxação dos inativos na proposta final, um dos pontos mais polêmicos de seu projeto original (Nakahodo \& Savoia, 2008, p. 52).

Importa notar, ainda, que os juízes foram importantes atores no momento posterior à aprovação da PEC, com a judicialização das demandas derivadas do inconformismo de setores sociais com o novo sistema previdenciário.

A discordância com as reformas não se restringiu aos magistrados. O Presidente enfrentou oposição em seu próprio partido, por uma questão programática: o Partido dos Trabalhadores historicamente defendeu conquistas sociais trabalhistas e foi, inclusive, um dos mais ferrenhos opositores de FHC durante a votação da EC 20/98.

A despeito das divergências partidárias, o cenário de Lula para implementação da reforma foi mais favorável do que as condições adversas que cercavam o Presidente anterior. De acordo com o trabalho de Nakahodo \& Savoia (2008, p. 48), "embora o debate em torno da reforma previdenciária tenha sido conduzido primordialmente no Congresso, muitos outros atores institucionais estiveram envolvidos na reforma". O Executivo Federal incluiu as alterações constitucionais dentre as prioridades de sua agenda, como se pode perceber no pronto encaminhamento da questão ao Legislativo - pouco tempo após o início do mandato.

Os Executivos Estaduais e Municipais também mostravam seu apoio, em virtude das diretrizes da Lei de Responsabilidade Fiscal, promulgada em 2001, que estabelecia "limites legais para os gastos públicos, levando prefeitos e, especialmente, governadores a defender a reforma previdenciária", com mais empenho do que ocorreu com a reforma anterior, quando o tema era incipiente (2008, p. 49).

Em ambas as reformas, não se pode desconhecer o papel da mídia, como relevante ator:

A imprensa foi capaz de mudar a natureza do debate ao influenciar a opinião pública, especialmente durante a reforma de Lula, de duas formas: primei- 
ro, ao trazer o assunto para uma audiência ampla, a mídia manteve a discussão na agenda política; segundo, ao colocar a questão previdenciária como solução para os problemas fiscais, em vez de se concentrar no corte de benefícios previstos pela Constituição, a imprensa ajudou a criar um ambiente propício para o debate sobre a reforma das aposentadorias do setor público (Nakahodo \& Savoia, 2008, p. 50).

Com a ajuda dos meios de comunicação, a opinião pública não constituiu empecilho para a aprovação da emenda em 2003, cujo trâmite decorreu celeremente. Já os organismos internacionais foram mais presentes na primeira reforma do que na segunda. Como, no período de 1995 a 1998, o Brasil se inseria num quadro de crise internacional, a reforma da previdência foi mais uma das medidas estabelecidas pelos fundos internacionais como necessárias para concessão de crédito.

Interessante papel, neste contexto, foi desempenhado pelas associações e sindicatos, principalmente aqueles que participaram ativamente da ascensão do Partido dos Trabalhadores à Presidência da República. A Central Única dos Trabalhadores (CUT) - fortemente ligada ao PT e representante dos interesses da maior parte dos servidores públicos -, opôs-se às reformas do sistema previdenciário. Já a Força Sindical (FS), tradicionalmente mais conservadora e próxima do setor privado, apoiou as reformas e expressou interesse em instituir seu próprio fundo de pensão. As associações de aposentados manifestaram-se no Conselho Nacional de Previdência Social, com pouco êxito. Em contrapartida, as associações representativas da classe empresarial foram aquelas que mais apoiaram as mudanças propostas, colaborando ativamente para sua aprovação em 2003 (Nakahodo \& Savoia, 2008).

As mudanças trazidas pela nova reforma atingiram principalmente os servidores estáveis e os recém-ingressos na Administração Pública. Algumas regras de transição foram alteradas, e consolidada maior aproximação entre as regras dos regimes próprios com o regime geral. Em resumo feito por Nakahodo \& Savoia, as alterações foram:
Para os servidores públicos na ativa, a idade mínima de aposentadoria foi mantida (53 anos para homens e 48 para mulheres), mas com uma redução de 5\% por ano, aplicada àqueles que decidissem se aposentar antes da idade de referência $(60$ e 55, para homens e mulheres, respectivamente), para aqueles que haviam ingressado no serviço público antes de 16 de dezembro de 1998. O benefício seria calculado com uma média das contribuições, tal qual no Regime Geral. Como incentivo para aqueles que decidissem adiar sua aposentadoria, um adicional de $11 \%$ foi incluído. Para os novos servidores, as regras serão semelhantes àquelas adotadas no Regime Geral, em que os benefícios seriam calculados com base no conjunto das contribuições anteriores, até o limite de $R \$$ 2.400,00, complementados por esquemas voluntários de contribuição. No caso dos aposentados do setor público, a principal mudança foi a taxação em $11 \%$ para aqueles cujos benefícios fossem superiores a $R \$ 1.440,00$, no serviço público federal, ou $R \$ 1.200,00$, para as demais esferas. A exceção ficou por conta daqueles portadores de direitos adquiridos, que permaneceriam livres do imposto. Para os trabalhadores do setor privado na ativa, os benefícios seriam elevados a $R \$ 2.400,00$, em comparação ao limite anterior de $R \$ 1.869,00$. A emenda também possibilitou a provisão da aposentadoria de um salário mínimo para trabalhadores de baixa renda. Para os futuros trabalhadores, o benefício de $R \$ 2.400$ foi mantido, com uma redução de $30 \%$ aplicada sobre o montante excedendo esse limite (2008, pp. 52-53).

Para completar o ciclo de alterações do sistema previdenciário brasileiro, em 2005 foi aprovada a Emenda Constitucional 47, conhecida como PEC Paralela, que trouxe alterações sobre a remuneração dos servidores públicos, mas também trouxe ajustes relativos à previdência. Seu principal propósito foi de conformar algumas alterações previstas pela EC 41/2003 que trouxeram perdas para os servidores que ingressaram em cargos públicos entre as Emendas 20/98 e 41/2003. Ela traçou novas regras de transição nestes casos e garantiu a paridade para eles; também ajustou regras sobre os fundos de pensão, em virtude do receio de que estes fossem utilizados para fins de corrupção (Mello, 2005). 


\section{$4 \quad$ A judicialização do conflito: "equilíbrio atuarial" $\mathrm{x}$ direitos adquiridos, 0 STF como garantidor da "governabilidade"?}

\subsection{Analisando as decisões judiciais: o conflito entre o equilíbrio atuarial e direitos adquiridos dos segurados}

O papel exercido pelas Cortes, de maneira geral, dentro da divisão de poderes na política e na sociedade é determinado pelo desenho institucional e pelos casos que são autorizadas a julgar (Kapiszewski, 2010). Por ser o responsável a responder sobre direitos e garantias fundamentais protegidos pela constituição, o STF tem que enfrentar o conflito gerado pelas mudanças no sistema previdenciário: de um lado, tem-se o Poder Executivo protegendo o orçamento futuro da previdência e, do outro, os segurados dos diversos regimes de previdência social que veem direitos sociais serem encolhidos (ou dificultados).

O respeito ao equilíbrio financeiro e atuarial é considerado um princípio da previdência social e foi introduzido no texto do artigo 201 da Constituição a partir da EC 20/98. Antes, a Lei 9.717/98, que fixava regras gerais para a organização e funcionamento dos RPPS, trouxe algumas limitações preocupada com o equilíbrio dos sistemas de regime próprio, como por exemplo, a proibição de concessão de benefícios distintos dos oferecidos pelo regime geral. Desde então, o equilíbrio financeiro e atuarial "tem sido invocado para o não atendimento de demandas pertencentes à previdência social, tanto para servidores públicos quanto do regime geral" (Rocha, 2004).

A defesa da União (e do INSS em casos concretos) tem por base, consequentemente, a preocupação com a fonte de custeio e o equilíbrio financeiro e atuarial. Para melhor compreensão, o equilíbrio financeiro está relacionado com o quanto se arrecada e quanto se paga em um ano financeiro. Para que as contas estejam equilibradas, o pagamento não pode ultrapassar a arrecadação. Enquanto que o equilíbrio atuarial se preocupa com as contribuições de um indivíduo ao longo da vida para que, ao se aposentar, ele consiga pagar seu próprio benefício (Rocha, 2004).

Por outro lado, os atores legitimados, ao ingressar com uma ADI neste tema, buscam defender a proteção contra os riscos sociais e o regime jurídico anterior à mudança de uma maneira geral. Cada legitimado defenderá, provavelmente, aquilo que é mais caro para sua classe ou seus interesses. Caberá ao STF definir o que irá prevalecer: a preocupação com o planejamento financeiro e atuarial da previdência ou os direitos sociais anteriormente previstos na constituição antes das alterações. Qual a função do STF nesta disputa?

Para compreender melhor o papel do Tribunal brasileiro, é preciso estudar seu comportamento a partir dos padrões das decisões judiciais; o que, segundo Taylor (2008), é fundamental para conhecer o efeito das cortes nas políticas públicas. Nesta pesquisa, as decisões do STF são analisadas a partir das seguintes variáveis: (a) autores das ações (legitimados); (b) princípios defendidos pelas partes; (c) princípio vencedor na soma dos votos dos Ministros.

O questionamento das Emendas 20/98 e 41/2003 levaram ao STF, no total, 30 ações diretas de inconstitucionalidade, de acordo com dados coletados da base de dados da pesquisa de Costa \& Benvindo (2014), produzida pela UNB. Destas ADI's: apenas 13 tiveram seu mérito julgado; 4 foram julgadas improcedentes; 1 não foi conhecida pelo relator; 3 não foram conhecidas pelo plenário; 1 teve seu seguimento negado pelo relator; em mais uma, a questão foi considerada prejudicada pelo relator; e, por fim, 3 foram consideradas procedentes em parte pelo plenário. As demais dezessete ainda aguardam julgamento. ${ }^{12}$

12 Os números das demais 17 (dezessete) ADIs são: 2096; 3363; 3308; 3297; 3184; 3133; 3143; 3855; 3872; 3998; 3854; 4014; 4802; $4803 ; 4887 ; 4888 ; 4889$. 


\begin{tabular}{|l|l|l|l|}
\hline ADI No & EC & Requerente & Decisão \\
\hline 1946 & 20 & Partido Político & Procedente em Parte (Plenário) \\
\hline 2024 & 20 & Governador de Estado & Improcedente (Plenário) \\
\hline 2242 & 20 & Assembleia Legislativa & Não Conhecida (Plenário) \\
\hline 2760 & 20 & Partido Político & Não Conhecida (Plenário) \\
\hline 2883 & 20 & Partido Político & Não Conhecida (Plenário) \\
\hline 3099 & 41 & Partido Político & Prejudicada (Decisão Monocrática) \\
\hline 3105 & 41 & Entidade Corporativa & Procedente em Parte (Plenário) \\
\hline 3128 & 41 & Entidade Corporativa & Procedente em Parte (Plenário) \\
\hline 3104 & 41 & Entidade Corporativa & Improcedente (Plenário) \\
\hline 3291 & 41 & Entidade Corporativa & Improcedente (Plenário) \\
\hline 3172 & 41 & Entidade Corporativa & Negado Seguimento (Decisão Monocrática) \\
\hline 3138 & 41 & Entidade Corporativa & Improcedente (Plenário) \\
\hline 3867 & 41 & Partido Político & Não Conhecida (Decisão Monocrática) \\
\hline
\end{tabular}

As treze ADI's que tiveram seu mérito julgado (acima listadas) serão objeto de análise para este trabalho, considerando-se seus acórdãos ou o motivo pelo qual elas não chegaram a plenário. 0 objetivo é analisar o papel do STF na conformação das reformas previdenciárias implementadas pelo Poder Executivo em 1998 e 2003.

\subsubsection{ADI 1946: teto para a licença maternidade}

A ação proposta pelo PSB questionava a constitucionalidade da alteração do artigo 14 da EC n 20/98, o qual impunha um limite máximo para o valor dos benefícios do regime geral de previdência social (teto). 0 partido alertou que se a previdência fosse obrigada a pagar todos os benefícios elencados no art. 201 até o teto estabelecido, as empresas teriam que complementar o excedente para as mulheres que se afastassem por licença maternidade. Caso o entendimento fosse mantido, as mulheres poderiam ser preteridas no mercado de trabalho.

A parte autora defendeu o princípio da igualdade e a proteção da mulher, o que foi corroborado pelo tribunal, entendendo-se que o constituinte derivado de 1998 não pretendeu voltar atrás na história com este direito (licença maternidade).

\subsubsection{ADI 2024: cargos em comissão,} temporários e empregos públicos como de contribuição obrigatória ao RGPS

Esta ADI tinha como objeto a alegação da inconstitucionalidade do art. 40 da CF, após a inclusão do $\S 13$ pela EC 20/98, sob fundamento da lesão ao pacto federativo brasileiro. A norma estabeleceu que os cargos em comissão, temporários e empregos públicos seriam de contribuição obrigatória ao Regime Geral de Previdência Social. Considerando que todos os entes federados, a partir da reforma, deveriam obrigatoriamente contribuir com o Regime administrado pela União, sofreriam limites em sua autonomia.

A justificação para a improcedência do pedido fundou-se em entendimentos anteriores do mesmo tribunal de que "as normas relativas às respectivas aposentadorias e pensões objetos dos seus (art. 40) respectivos parágrafos (...) e toda a disciplina constitucional originária do regime dos servidores públicos - inclusive a do seu regime previdenciário - já abrangia os três níveis da organização federativa (...)".

Assim, o STF rejeitou a teoria do Governador do estado do Mato Grosso do Sul (legitimado) sobre ataque ao federalismo uma vez que sempre coube à União 
administrar a previdência social geral e a nova norma versava sobre os empregados celetistas (cargos em comissão, empregados públicos) e não aqueles regidos pelo regime jurídico estatal.

\subsubsection{ADI 2242: aposentadoria de Magistrados} Ação proposta pela Mesa da Assembleia Legislativa do Estado do Paraná que questiona a constitucionalidade da nova redação dada ao art. 93, VI da Constituição pela EC n. 20/98. O artigo trata sobre a aposentadoria dos magistrados, agentes políticos do Poder Judiciário. O Ministro Relator da ADI entendeu pelo não conhecimento da ação, inicialmente por conta da falta de pertinência temática, requisito aplicável a este autor. As mesas das Assembleias Legislativas precisam comprovar pertinência entre o pedido e a atividade e/ou interesse do legitimado.

O segundo argumento utilizado pelo relator, Ministro Moreira Alves, para não conhecer da ação diz respeito à fundamentação jurídica apresentada pelo autor para atacar a nova redação do referido artigo. $\mathrm{Na}$ verdade, não teria ocorrido alteração de conteúdo, mas mera "transferência" da aposentadoria dos magistrados para o art. 40. Em linhas gerais, a nova redação dada pela EC 20/98 deixou a situação dos juízes da mesma forma: aposentadoria por invalidez; aposentadoria por tempo de contribuição após trinta anos e aposentadoria compulsória aos 70 anos de idade (mais um elemento atacado na inicial).

$\mathrm{O}$ argumento do autor se baseou no ataque à garantia de vitaliciedade (art, 95, I); no entanto, o texto originário já previa essa possibilidade, sem qualquer reversão. In casu, a ação foi considerada improcedente.

\subsubsection{ADI 2760: aposentadoria compulsória dos Magistrados e Ministros do TCU}

A ADI 2760 também versa sobre a possível inconstitucionalidade do texto que trata sobre a aposentadoria compulsória dos magistrados e incluiu os Ministros do Tribunal de Contas da União sob o mesmo regramento. Dessa vez, a ação foi proposta pelo Partido Social Liberal (PSL). A alegação consistia na violação ao princípio da isonomia, pois não havia previsão para aposentadoria compulsória para os membros (agentes políticos) do Poder Executivo e do Poder Legislativo. A ação também não foi conhecida e o Mi- nistro Relator, Joaquim Barbosa, afirmou que não é possível alegar inconstitucionalidade de texto original da Constituição.

Interessante notar, no texto do seu relatório (fls. 154), que o Relator menciona ser contrário ao entendimento de que é possível alegar inconstitucionalidade de texto de emendas à Constituição, mas ele aceita por ser jurisprudência da Corte.

Outra anotação importante a ser apontada no texto do relatório é o que se encontra às fls. 155: "[a aposentadoria compulsória] decorre de opção político-institucional [...] por razões de técnica de controle concentrado, o Tribunal criaria nova norma constitucional ao acolher o pedido, sem competência para fazê-lo" (grifos nossos).

Nesse momento, o Ministro Joaquim Barbosa usou como um dos argumentos para não dar uma decisão sobre a matéria a possibilidade de o Tribunal criar norma nova e invadir a competência do Legislativo. Um argumento típico de autocontenção que remonta ao papel do STF protetor ao manter o espaço institucional reservado às decisões do Executivo.

\subsubsection{ADI 2883: aposentadoria compulsória dos Magistrados e Ministros do TCU}

O Partido Verde também sustentou a inconstitucionalidade da regra sobre a aposentadoria compulsória dos magistrados, membros do TCU e, neste caso, também os procuradores do Ministério Público, todos agentes políticos. Vale ressaltar que esta regra já existia anteriormente, mas era tratada no artigo 73 e 93; a EC 20/98 levou a regra ao artigo 40 que trata da aposentadoria dos agentes públicos.

A alegada inconstitucionalidade, novamente, é a suposta falta de isonomia no tratamento dado aos agentes políticos do Poder Judiciário, TCU e Ministério Público comparados aos membros agentes políticos do Poder Executivo e Legislativo.

A questão não foi conhecida em preliminar, mas o relator Gilmar Mendes quis tratar do mérito em plenário para que o STF se posicionasse quanto ao tema, uma vez que este tópico já estava sendo debatido em controle difuso e de maneira diversa. O que se pode destacar é que ele diz, em relatório, que servidores públicos 
não possuem direito adquirido a regime jurídico de aposentadoria. A mudança no regime é escolha política dos Poderes Legislativo e Executivo. Se houver a necessidade de recálculo atuarial para a sustentabilidade do sistema, a lei poderá ser alterada e, quem está vinculado ao regime, terá que suportar as mudanças.

\subsubsection{ADI 3104 e 3291: alterações nos critérios} de idade e tempo para aposentação

A ação 3291 foi apensada à 3104 por ter o mesmo objeto. O julgamento da ação proposta pela Associação Nacional dos Membros do Ministério Público em face de possível inconstitucionalidade do art. $2^{\circ}$ e expressão " 8 a" do art. 10, ambos da Emenda Constitucional 41/2003 trouxe um debate bem acirrado entre os ministros. $\mathrm{O}$ art. $2^{\circ}$ da nova Reforma da Previdência trouxe novas regras de transição para os servidores públicos que ainda não haviam completado os requisitos necessários para aposentadoria ao tempo da emenda. Novamente, assim como foi em 1998, houve mudanças nos critérios de idade e tempo para aposentação e novos critérios de transição.

$\mathrm{O}$ argumento dos requerentes era de que haveria direito adquirido para os servidores que já estavam no serviço público à época da emenda 20 de 1998 e que já tiveram que se contentar com regras novas naquele momento.

O motivo do indeferimento por parte da Ministra Relatora Carmen Lúcia fundamentou-se no entendimento muitas vezes repetido pela Corte de que só há direito adquirido para aposentadoria quando se completam todos os requisitos exigidos pela Constituição e pelas normas infraconstitucionais. Assim seguiram aqueles Ministros que votaram com ela.

Vale chamar a atenção para o relatório do Ministro Menezes Direito, que salientou o argumento sustentado em tribuna pelo Advogado-Geral da União sobre o equilíbrio financeiro e atuarial: "ninguém discute mais hoje que o regime previdenciário tem natureza contributiva e solidária e, ao mesmo tempo, que deve levar em conta o equilíbrio financeiro e atuarial".

Voto vencido, mas apaixonado, foi o de Carlos Brito. Ele defendeu que não parece razoável nem proporcional admitir que servidores públicos ingressem, por concurso público no serviço público, debaixo de certas regras assecuratórias de uma dada aposentadoria ou pensão, e tudo isso fique inteiramente à disposição da entidade mantenedora do sistema de previdência.

O Ministro Gilmar Mendes, apesar de votar com a relatora, faz uma ponderação importante. Ele expõe sua preocupação com o argumento do "direito adquirido", uma vez que em breve não será suficiente mantê-lo. Segundo Mendes, a Corte já o utilizou bastante com a emenda 20/98 e, agora (então) com a emenda 41/2003, quando ambas apresentaram cláusulas de transição para os servidores que ainda não haviam adquirido o direito subjetivo. E arremata: "consolidando aquilo que chamei aqui de corrida de obstáculos com obstáculo em movimento".

O Ministro Carlos Brito, aproveitando o comentário do Gilmar Mendes insurge-se contra a postura dos que acompanham o voto da relatora para lembrar a fragilidade do sistema quando ele traz sucessivas regras transicionais e a ameaça à segurança jurídica. Cezar Peluso expôs a discussão de forma contundente: "mas não é só uma questão de segurança jurídica, o problema, também, é a avaliar o custo e a viabilidade econômica de certas prestações estatais..." (grifos nossos).

Voto divergente também foi apresentado pelo Ministro Marco Aurélio, mas dentro da sua fundamentação o que é de interessante anotação é a "provocação" apontada para o então presidente Luís Inácio que, segundo o Ministro:

todo governante que alcança o poder, principalmente o poder maior, tem o seu plano de governo, as suas medidas milagrosas para chegar-se a novos dias. Sempre se imagina a necessidade de nova normatização - a meu ver, o que nós precisamos, no Brasil, é de homens, principalmente de homens públicos, que observem o ordenamento jurídico em vigor.

Uma provocação, pois, que reflete a surpresa que causou a EC 41/2003 ter sido proposta por um presidente que, enquanto líder do partido de oposição, tanto criticou a primeira reforma de 1998. 


\subsubsection{ADI 3105, ADI 3099 e ADI 3128:} contribuição de inativos

A contribuição cobrada dos inativos e pensionistas que recebem acima do teto remuneratório constitucional, regra introduzida pelo art. $4^{\circ}$ da EC 41/2003, foi um dos pontos mais controvertidos daquele processo de reforma do texto. Como esperado à época da promulgação da citada emenda, a questão foi judicializada, com o ajuizamento de ação direta de inconstitucionalidade pela Associação Nacional dos Membros do Ministério Público.

O julgamento da ADI 3105 precedeu a apreciação meritória da ADI 3104 e trouxe uma discussão ainda mais ampla no âmbito do STF - espelhado no acórdão, que possui 327 páginas.

A Min. Relatora Ellen Gracie foi voto vencido no caso, mas fez uma longa exposição quanto ao histórico da previdência até a Emenda 41/2003, além de fundamentar seu voto na teoria de que a tributação exigida aos aposentados feriria o "sinalagma da relação previdenciária”, ou seja, o trabalhador contribui para poder se aposentar um dia. Uma vez aposentado, ele já teria "feito sua parte", de modo que caberia ao regime oferecer sua contrapartida.

Ao final, o STF julgou improcedente o pedido em relação ao caput do art. $4^{\circ}$, mas julgou inconstitucionais as expressões "cinquenta por cento" e "sessenta por cento" dos incisos I e II do parágrafo único do mesmo dispositivo. Assim, a contribuição previdenciária recaiu, de maneira idêntica, sobre os proventos dos inativos e pensionistas dos Estados, Municípios, Distrito Federal e da União.

\subsubsection{ADI 3138: limites para alíquotas de contribuição social}

A ação questiona a validade constitucional do art. $1^{\circ}$ da Emenda Constitucional n. 41/2003, na parte em que incluiu o $\S 1^{\circ}$ no art. 149 da Constituição da República, por pretensa contrariedade aos arts. $24, \S 1^{\circ}$, 25, § $1^{\circ}$, e $60, \S 4^{\circ}$, inc. I, da Constituição da República: ou seja, afrontaria o pacto federativo, o princípio do equilíbrio atuarial e a autonomia dos Estados. 0 dispositivo determina que a alíquota cobrada pelos regimes dos servidores dos Estados, Distrito Federal e Municípios não será inferior à da contribuição dos servidores titulares de cargos efetivos da União.

A ação foi julgada improcedente, porque:

A norma que fixa alíquota mínima (contribuição dos servidores titulares de cargos efetivos na União) para a contribuição a ser cobrada pelos Estados, pelo Distrito Federal e pelos Municípios de seus servidores, para o custeio, em benefício destes, do regime previdenciário de que trata o art. 40 da Constituição da República não contraria o pacto federativo ou configura quebra de equilíbrio atuarial. E a observância da alíquota mínima fixada na Emenda Constitucional n. 41/2003 não configura quebra da autonomia dos Estados Federados. O art. 201, § 9०, da Constituição da República, ao estabelecer um sistema geral de compensação, há ser interpretado à luz dos princípios da solidariedade e da contributividade, que regem o atual sistema previdenciário brasileiro.

A autora da ação foi a Associação de Magistrados do Brasil. Durante as arguições, foi levantado um dos motivos para os quais esta medida seria importante para os regimes: a alíquota da contribuição previdenciária estava virando, no Brasil, "moeda de troca" ou promessa de campanha em muitos municípios e alguns estados. Dessa forma, os vencedores diminuíam a alíquota para agradar os servidores, ainda que pusessem em risco todo o sistema de previdência. Este foi um dos argumentos que levou, por exemplo, o Ministro Luiz Fux a votar pela improcedência do pedido:

É verdade que ouvi, aqui da Tribuna, que, em nome dessa independência e autonomia das unidades da Federação, há até unidades que isentam de pagamento dessa contribuição. Pela experiência que eu tenho do meu Estado - e aqui foi citado o meu Estado -, essa estratégia de isentar os pensionistas dessa alíquota mínima representou o que, no Rio de Janeiro, se considera um desastre eleitoreiro, tanto que agora há um projeto de lei, que foi aprovado ontem na Câmara com manifestações contrárias, para instituir essa contribuição na medida em que o sistema previdenciário sobrevive do caráter solidário e universal, que lhe é peculiar (Fux, voto, p. 12). 


\subsubsection{ADI 3172: contribuição de inativos}

A ANAMATRA - Associação Nacional de Magistrados da justiça do Trabalho também ingressou com ADI contra a alteração da EC 41/03 que trouxe a obrigatoriedade da contribuição dos inativos que recebem acima do teto do RGPS. Contudo, a Ministra relatora, Carmen Lúcia, considerou o pedido improcedente por ilegitimidade da parte autora, pois a alteração afeta a todos os magistrados, não apenas a magistratura do trabalho.

\subsubsection{ADI 3867: inaplicabilidade dos novos} paradigmas constitucionais à categoria de Fiscal de Rendas do Estado do Rio de Janeiro

Não foi conhecida, pois, segundo a Ministra relatora, a ação não buscava, efetivamente, o controle abstrato de constitucionalidade, mas decisão judicial para atendimento de interesses subjetivos específicos. A ADI foi apresentada pelo PDT e, apesar de questionar a constitucionalidade dos artigos $8^{\circ}$ e $9^{\circ} \mathrm{da}$ Emenda Constitucional no 41, de 19.12.2003, e os artigos $3^{\circ}$ e $5^{\circ}$ da Emenda Constitucional no 19 , de 04.06 .1998 , o objetivo mesmo da ação seria requerer a inaplicabilidade dos novos paradigmas constitucionais à categoria de Fiscal de Rendas do Estado do Rio de Janeiro, em razão de serem os mesmos beneficiados com decisão judicial transitada em julgado (fls. 204).

\section{Considerações finais: Repensando a Judicial Politics e o ativismo judicial no Brasil}

Nota-se que de maneira geral as ações foram julgadas improcedentes em seus pedidos, no entanto, o STF buscou atenuar algumas desigualdades trazidas pelas reformas, pontualmente. Por exemplo, a ADI 1946, cuja decisão foi de proteger as mulheres para que os salários maternidade não fossem atingidos pelo teto previdenciário. As ADI's 3105 e 3128 também consideraram inconstitucionais as alterações previstas pela reforma que tratavam de maneira diferente os servidores da União e dos Estados, Distrito Federal e Municípios.

Em resumo, o resultado foi o seguinte:

Tabela 2. Princípios "vencedores"

\begin{tabular}{|c|c|c|c|c|}
\hline ADI No & EC & Requerente & Decisão & Princípio "vencedor" \\
\hline 1946 & 20 & Partido Político & Procedente em Parte (Plenário) & $\begin{array}{l}\text { Proteção contra os riscos } \\
\text { sociais. }\end{array}$ \\
\hline 2024 & 20 & Governador de Estado & Improcedente (Plenário) & $\begin{array}{l}\text { Limites constitucionais ao } \\
\text { poder reformador }\end{array}$ \\
\hline 2242 & 20 & Assembleia Legislativa & Não Conhecida (Plenário) & Falta de pertinência temática \\
\hline 2760 & 20 & Partido Político & Não Conhecida (Plenário) & $\begin{array}{l}\text { Norma constitucional origi- } \\
\text { nária }\end{array}$ \\
\hline 2883 & 20 & Partido Político & Não Conhecida (Plenário) & $\begin{array}{l}\text { Norma constitucional origi- } \\
\text { nária }\end{array}$ \\
\hline 3099 & 41 & Partido Político & Prejudicada (Decisão Monocrática) & $\begin{array}{l}\text { Equilíbrio financeiro e atu- } \\
\text { arial }\end{array}$ \\
\hline 3105 & 41 & Entidade Corporativa & Procedente em Parte (Plenário) & $\begin{array}{l}\text { Equilíbrio financeiro e atu- } \\
\text { arial }\end{array}$ \\
\hline 3128 & 41 & Entidade Corporativa & Procedente em Parte (Plenário) & $\begin{array}{l}\text { Equilíbrio financeiro e atu- } \\
\text { arial }\end{array}$ \\
\hline 3104 & 41 & Entidade Corporativa & Improcedente (Plenário) & $\begin{array}{l}\text { Equilíbrio financeiro e atu- } \\
\text { arial }\end{array}$ \\
\hline 3291 & 41 & Entidade Corporativa & Improcedente (Plenário) & $\begin{array}{l}\text { Equilíbrio financeiro e atu- } \\
\text { arial }\end{array}$ \\
\hline 3172 & 41 & Entidade Corporativa & $\begin{array}{l}\text { Negado Seguimento (Decisão Monocrá- } \\
\text { tica) }\end{array}$ & Falta de pertinência temática \\
\hline 3138 & 41 & Entidade Corporativa & Improcedente (Plenário) & $\begin{array}{l}\text { Princípios solidariedade e } \\
\text { contributividade }\end{array}$ \\
\hline 3867 & 41 & Partido Político & Não Conhecida (Decisão Monocrática) & $\begin{array}{l}\text { Impossibilidade de Análise } \\
\text { em ADI }\end{array}$ \\
\hline
\end{tabular}


Cinco das treze ações foram julgadas tendo o princípio do equilíbrio financeiro e atuarial como fundamento, dentre outros princípios. Apenas uma ação foi julgada para proteger a população dos riscos sociais envolvidos na mudança. No caso, a ADI 1946 evitou um retrocesso nos direitos trabalhistas femininos ao entender que o teto da previdência não recairia sobre a licença maternidade.

As demais ações foram consideradas improcedentes ou não foram conhecidas ou, ainda, tiveram seu seguimento negado pelos mais diversos motivos: a norma a ser considerada inconstitucional pertencia ao texto originário da constituição; ${ }^{13}$ ou não foi comprovada pertinência temática entre o pedido e a atividade do legitimado; ou, por fim, o caso não cabia em controle abstrato. Há ainda a defesa dos princípios da solidariedade e da contributividade que dizem, respectivamente, que, no sistema previdenciário, quem contribui hoje sustenta os benefícios das gerações passadas e que a previdência não é gratuita.

Registra-se, ademais, que, não obstante haver três procedências parciais, apenas uma delas realmente garantiu direitos sociais. Duas referentes à contribuição dos inativos apenas excluíram o tratamento diferenciado entre os diversos regimes, extraindo do texto as porcentagens diferenciadas.

Finalmente, levar o debate político à arena judicial é um recurso incorporado ao Estado Democrático de Direito, cada vez mais utilizado pelos atores políticos e sociais. Quando não há como se evitar a aprovação de uma norma no Legislativo, ainda é possível lutar pela declaração de inconstitucionalidade da mesma no STF. As reformas da previdência foram realizadas em momentos diferentes, em cenários distintos. A primeira enfrentou mais dificuldades para sua aprovação, mas ambas foram judicializadas posteriormente.

$\mathrm{Na}$ análise das ADI's com mérito julgado, percebe-se a preocupação do STF em atuar como legislador negativo, preservando, neste caso, a reserva de governo. $O$ grande obstáculo jurídico às reformas no Poder Legislativo foram a garantia do direito adquirido - e sua construção na jurisprudência do próprio STF e o princípio da segurança jurídica. No entanto, em matéria previdenciária, o STF firmou entendimento de que não há direito adquirido a regime de previdência, sendo este uma escolha política, e as mudanças são necessárias para a preservação do equilíbrio financeiro e atuarial.

Estes fatores, juntamente com outros aspectos, foram enfrentados nas decisões. Foi possível, através da análise legal, notar a incorporação de argumentos de governo nas decisões, consubstanciados na adesão ao princípio constitucional do pacto federativo e à regra do equilíbrio financeiro e atuarial. Interessante perceber que, na contramão dos dados coletados, a conhecida sensibilidade do STF aos argumentos expostos pelos agentes do direito (magistratura e MP, sobretudo) não foi suficiente para reverter o aparente compromisso do tribunal com as preferências do Poder Executivo.

HIIIIIIIIIIIIIIIIIIIIIIIIIIIIIIIII

Data de submissão/Submission date: 06.04.2016

Data de aprovação/Acceptance date: 08.09.2016 


\section{Referências}

Andrade, L. D. de. (2015). Agenda-Setting: Análise do comportamento do Supremo Tribunal Federal no controle de constitucionalidade concreto. Recife: UNICAP/Programa de Pós-graduação em direito. Dissertação de mestrado.

AVERBUG, André; GIAMBIAGI, Fábio. A Crise Brasileira de 1998/1999 - Origens e Consequências. BNDES: Rio de Janeiro, 2000. Disponível em: http://www. bndes.gov.br/SiteBNDES/export/sites/default/ bndes_pt/Galerias/Arquivos/conhecimento/td/ Td-77.pdf. Acesso em: 10 nov. 2016.

Brasil. (2014). Fator Previdenciário: cálculo de aposentadorias. Ministério da Previdência Social. Disponível em: <http://www.previdencia.gov.br/ servicos-ao-cidadao/informacoes-gerais/valor-aposentadorias>. Acesso em: 17 ago. 2016.

Campos, M. B. L. B. (2011). Regime próprio de previdência social dos servidores públicos. 3. ed. Curitiba: Juruá.

Carvalho Neto, E. R. (2005). Revisão abstrata da legislação e judicialização da política no Brasil. São Paulo: USP/Departamento de Ciência Política, Tese de doutoramento.

Costa, A. A. \& Benvindo, J. Z. (2014). A Quem Interessa o Controle Concentrado de Constitucionalidade? o Descompasso entre Teoria e Prática na Defesa dos Direitos Fundamentais (Relatório da pesquisa). Brasília: UNB/CNPQq. Disponível em: <http:// www.ufj.br/siddharta_legale/files/2014/07/Alexandra-Costa-e-Juliano-Zaiden-a-quem-interessa-o-controle.pdf $>$. Acesso em: 20 jul. 2014.

Friedman, B. (2005). The Politics of Judicial Review. Texas Law Review, v. 84, n. 2, pp. 257-337, dec.

Kapiszewski, D. (2010). Arbitro de conflictos, creador de políticas públicas, o protector de derechos? El Supremo Tribunal Federal de Brasil em transición. In: Helmke, G. \& Ríos Figueroa, J. Tribunales constitucionales em America Latina. Mexico, D.F.: Suprema Corte de Justicia de La Nación.

Mello, M. A. C. (2005). Análise da Emenda Constitucional no 47 de 2005. Câmara dos Deputados. Disponível em: <http://www2.camara.leg.br/ documentos-e-pesquisa/publicacoes/estnottec/ tema1/2005_9810.pdf>. Acesso em: 19 mai. 2015.

Nakahodo, N. \& Savoia, J. R. S. (2008). A reforma da previdência no Brasil: estudo comparativo dos governos Fernando Henrique Cardoso e Lula.
Revista Brasileira de Ciências Sociais, fev. Disponível em: <http://www.redalyc.org/articulo. oa?id=10706603>. Acesso em 13 mai. 2015.

Pinheiro, A. C. P. (2005). Judiciário, reforma e economia: a visão dos magistrados. Disponível em: <http://www.febraban.org.br/Arquivo/Destaques/Armando_Castelar_Pinheiro2.pdf>, p. 20. Acesso em: 20 mai. 2015.

Ribeiro, R. S. (2012). Política e Economia na Jurisdição Constitucional Abstrata. Revista Direito GV, v. 8. São Paulo, jan-jun.

Rocha, D. M. (2004). O Direito Fundamental à Previdência Social: na perspectiva dos princípios constitucionais diretivos do sistema previdenciário brasileiro. Porto Alegre: Livraria do Advogado.

Sundfeld, C. A. et al. (2010). Controle de constitucionalidade e judicialização: o STF frente à sociedade e aos Poderes. Belo Horizonte: Faculdade de Filosofia e Ciências Humanas. Projeto Observatório da Justiça Brasileira. Ministério da Justiça. Disponível em: <http://democraciaejustica.org/ cienciapolitica3/sites/default/files/controle_de_ constitucionalidade_e_judicializacao.pdf $>$. Acesso em: 18 nov. 2011, p. 28.

Taylor, M. M. (2007). O judiciário e as políticas públicas no Brasil. DADOS - Revista de Ciências Sociais, Rio de Janeiro, v. 50, n. 2, pp. 229-257. Disponível em: <http://www.scielo.br/pdf/dados/v50n2/ a01v50n2.pdf>. Acesso em 20 mai. 2015. (2008). Judging Policy: Courts and Policy Reform in democratic Brazil. Stanford University Press: Stanford, California.

Taylor, M. M. \& Da Ros, L. (2008). Os partidos dentro e fora do poder: a judicialização como resultado contingente da estratégia política. DADOS - Revista de Ciências Sociais, Rio de Janeiro, v. 51, n. 4, pp. 825-864, pp. 840-842.

VIANNA, Luiz Werneck et al. A judicialização da política e das relações sociais no Brasil. Rio de Janeiro: luperj/Revan, 1999.

Vianna, L. W.; Burgos, M. B. \& Salles, P. M. (2007). Dezessete anos de judicialização da política. Tempo Social (Revista de Sociologia da USP), v. 19, n. 2, pp. 39-85. Disponível em: <http://www.scielo.br/ $\mathrm{pdf} / \mathrm{ts} / \mathrm{v} 19 \mathrm{n} 2 / \mathrm{a} 02 \mathrm{v} 19 \mathrm{n} 2 . \mathrm{pdf}>$. Acesso em $22 \mathrm{jul}$. 2015. 